\title{
Design of the Test Platform of Servo System
}

\author{
Yong-guang Liu \\ School of automation science and electric engineering \\ Beihang University \\ Beijng, China, 13681055187 \\ lyg@buaa.edu.cn
}

\begin{abstract}
This paper designs a test platform of servo system. The technique method of the test platform of servo system is studied, the structure diagram of the test platform of servo system is given; the way of loading friction resistance torque and moment of inertia respectively are designed, which realizes changing the friction resistance and moment inertia of the system; the realtime measurement and control system based on the Lab Windows/CVI and RTX is designed, which realizes the real-time control; the test platform can truly simulate the actual load of the servo system, assess dynamic and static technology index of the servo system.
\end{abstract}

Keywords-servo system; friction resistance torque load; moment of inertia load; real-time control

\section{INTRODUCTION}

Along with the development of the manufacturing industry in weapons, the test platform of servo system is used as the experimental tool which can test the performance of a weapon system, the application of the test platform of servo system is more and more extensive, it can simulate system working conditions, assesses servo system of the dynamic and static technology index, which can be used as the production guidance and basis. Experimental platform can truly simulate various frictional resistance of the servo system, reproduce the motion of dynamic characteristics, so it is significant to research system performance and improving system specifically[1] [2]. The test platform of servo system can load the moment inertia and friction resistance torque, it can test some performance indicators of the servo system, such as torque, angle, angular velocity, angular acceleration, etc. Replacing the loading inertia dish can realize the moment of inertia load, using magnetic powder brake loading method can realize friction resistance torque load. The measurement and control system is based on LabWindows/CVI and RTX, it can realize real-time and reliable control.

\section{Mechanical Structure of THE System}

Mechanical structure is shown in Figure 1. The test platform of servo system consists of reducer box, the motor load system, friction resistance torque load system, the moment inertia load system, the lubrication system.

\author{
Qin Lei \\ School of automation science and electric engineering \\ Beihang University \\ Beijng, China, 15201149008 \\ thunderation@163.com
}

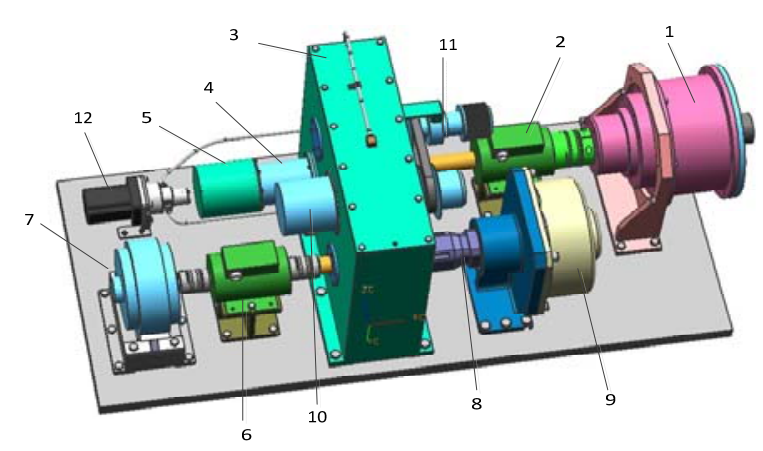

Note: 1-motor 2-torque sensor 13 -reducer 4-rotary encoder 1 5-fiber optic gyroscope 6-torque sensor 2 7-magnetic powder brake 8-planetary reducer 9inertia dish 10-rotary encoder 2 11-step less variator 12-motor pump

Figure 1. Mechanical structure

There are three gears in the reducer box, the specific position is shown in Fig 2. As the driving gear, gear 1 drives gear 2 and gear 3, a fiber optic gyroscope which measures the system angular velocity and a rotary encoder 1 are installed on the output termination of gear 1.The output termination of the gear 3 is used as the driving wheel of the step less variator, the driven wheel of step less vatiator is linked with the rotary encoder 2. By computing the ratio between rotary encoder 1 and rotary encoder 2 , the transmission ratio of the step less variator is get, which is also the transmission ratio of the system. In order to increase the service life of the gear and the transmission efficiency, there is lubrication system in reducer box.

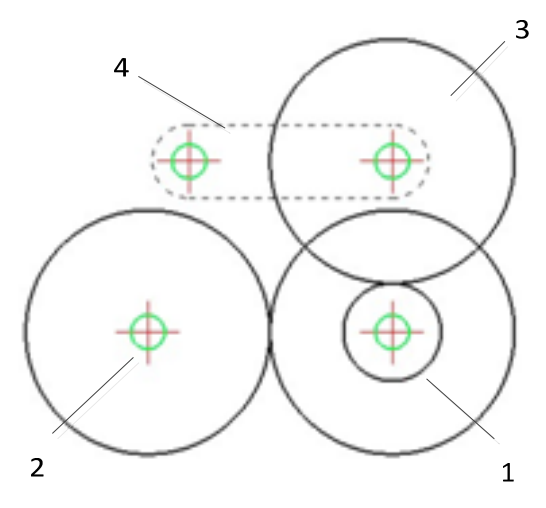

1-gear 1 2-gear 2 3-gear 3 4-step less variator

Figure 2. Reducer gear locations 


\section{MOMENT OF INERTIA LOAD}

Inertial load is produced when object makes the variable speed movement, and when the controlled object makes the rotary motion, the object create the inertia of torque:

$$
M_{L}=-J_{L} \dot{\Omega}
$$

where $\mathrm{J}_{\mathrm{L}}$ is the moment of inertia when the controlled object rotates around the shaft, $\Omega$ is the angular velocity.

This system changes the inertia disk to realize loading the moment of the inertia, inertia disk is added in the motor output shaft directly, so that we can make the system structure more compactly, it is viable to the change inertia disk or the number of inertia dish to change the system inertia. All inertia of the system (including gear, transmission shaft, sensors, etc) should be converted to the motor shaft, we can get the foundation inertia of the system, which is $8.05 \times 10^{-4} \mathrm{~kg} \cdot \mathrm{m}^{2}$, the inertia needed to load is the inertia of the inertia disk and the foundation inertia of system. If the loading inertia is very big, the space where the inertia disk is installed will be so big that it can't be installed. The system takes the method of installing planetary reducer between the reducer box and the inertia disk, inverting the planetary reducer makes the speed up, it can realize loading large inertia and meet the installation requirements

\section{FRICTION RESISTANCE TORQUE LOAD}

There are many ways to load friction resistance torque, the common ways are: direct current generators load, electrohydraulic servo unit load and magnetic powder brake load[3]. The method of direct current generator load has the characters of big armature current, great power of the variable resistance box, big volume, and it is hard to load the forward, backward torque. The method of electro-hydraulic servo unit load will produce excess torque, the excess torque has seriously affected control performance and loading precision of the system. The magnetic powder brake load has the advantage of there being an approximative linear relationship between its transmission torque and the exciting current, torque can be changed by changing the current, and the adjusting range is extensive, control for the precision is more precise, simple methods can be used to achieve large torque range of adjustment. The magnetic powder brake is based on the electromagnetic principle and uses magnetic powder transmitting torque. It can transfer constant torque, and has the advantage of high response speed, simple structure, no pollution, no noise, no impact and vibration, energy saving, etc. The flux growth of magnetic powder brake depends on the inductance in the magnet exciting coil, it can be approximately treated as a first order inertia link. The magnetic powder brake open-loop transfer function may be described as follows:

$$
\mathrm{G}_{\mathrm{m}}(s)=\frac{T_{m}(s)}{I_{m}(s)}=\frac{K_{m}}{T_{1} s+1} e^{-\tau s}
$$

where $K_{m}$ is the gain of magnetic powder brake, $\tau$ is the retardation time, $\mathrm{T}_{1}$ is the time constant.

The closed loop diagram of friction resistance torque load is shown in figure 3.

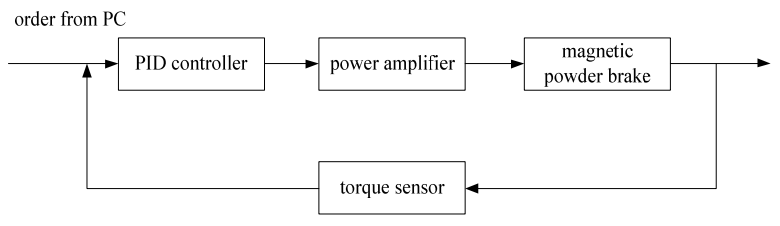

Figure 3. Closed loop diagram of friction resistance torque load

A step torque signal which is $2 \mathrm{~N} \cdot \mathrm{m}$ is sent to the magnetic powder brake at $0.1 \mathrm{~s}$, the result is shown in figure 4 .

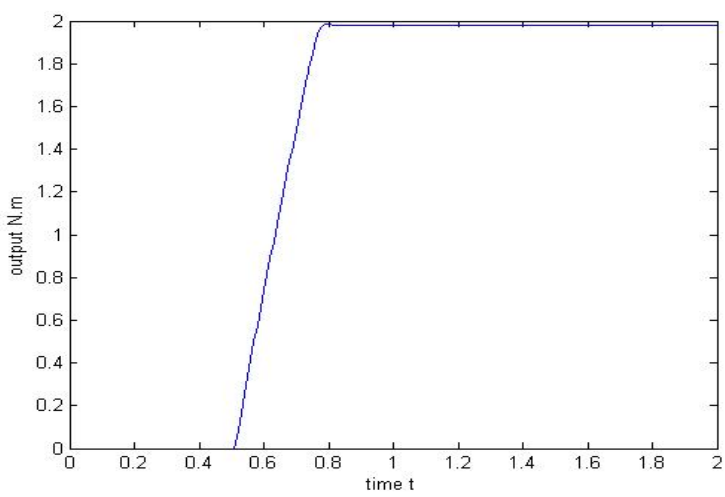

Figure 4. Simulation results

\section{Design Of The MeAsurement AND CONTROL System}

The system uses the Windows real-time operating system with RTX as the software platform. RTX is the Windows realtime extended system made by Ardence, it provides a real-time subsystem in the Windows platform, RTX is placed inside the Windows operating system, it enhances the system real-time without impacting on original function of the Windows. RTX subsystem module has independent clock and timer, it has high resolution, its precision can reach $1 \mu \mathrm{s}$. RTX has the perfect process management, it can fully realize the $0 \sim 127$ process priority, the development environment is simple, which can significantly short the development cycle. RTX realized the certainty of real-time thread scheduling, the process of communication mechanism between the real-time environment and the original Windows environment and the extended character of the Windows system which only exists in particular real-time operating system[4] [5].

System selects LabWindows/CVI as the development tools of upper software. LabWindows/CVI is the interactive C language development platform which released by the National Instruments designing the virtual instrument. It combines the powerful and flexible $\mathrm{C}$ language with the professional measurement and control tool which is used for data acquisition analysis, it provides an ideal software development environment to the developers who are familiar with the $\mathrm{C}$ language to build detection system, automatic test environment, data collection system, process monitoring system and virtual instrument. The biggest advantage of the development software lies in flexible application and powerful expandability, it allows 
users to develop the application program that the operation is simple and the interface is user-friendly in short time[6] [7].

Diagram of the measurement and control system is shown in figure 5. Data acquisition card PCI-1716 acquires the torque of motor output and magnetic powder brake and the angular velocity of system through the fiber optic gyroscope, we can get the angular acceleration of the system through difference angular velocity of the system. Counter card IK220 acquires angle signal from rotary encoder 1 and rotary encoder 2 . Control command is sent from the DA card PCI-1723 to power amplifier, finally it realizes controlling the magnetic powder brake. In addition, the control signal of the motor is also sent from PCI-1723. Data acquisition card PCI-1716, counter card IK220, DA card PCI-1723 are all interface card which use PCI bus.

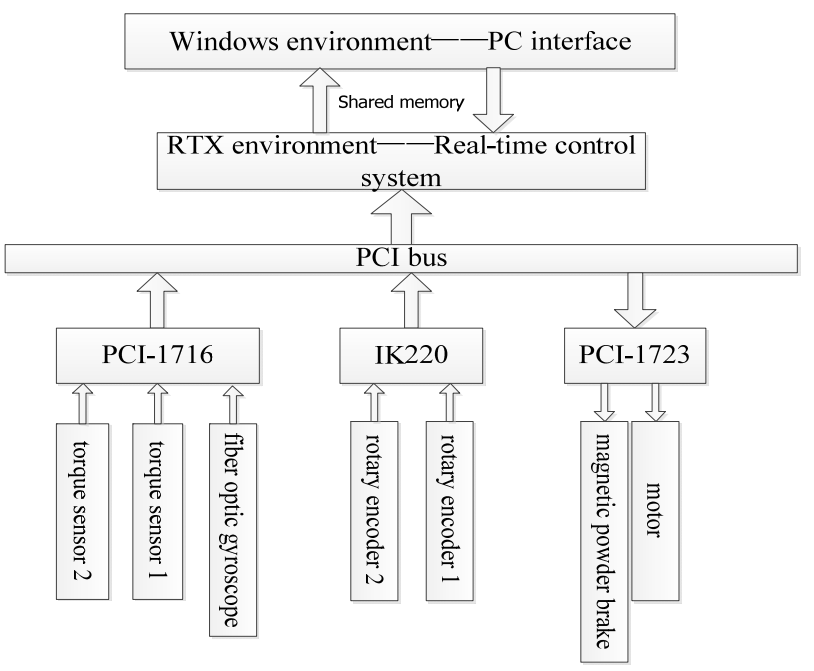

Figure 5. Diagram of the measurement and control system

The system uses the real-time data acquisition technology which is based on the Lab Windows/CVI and RTX, it has the advantage of real-time control and high reliability, the virtual instrument software contains rich interface, the interface is simple and friendly, and it's convenient for user operation and observation. Interface of the measurement and control system is shown in figure 6.

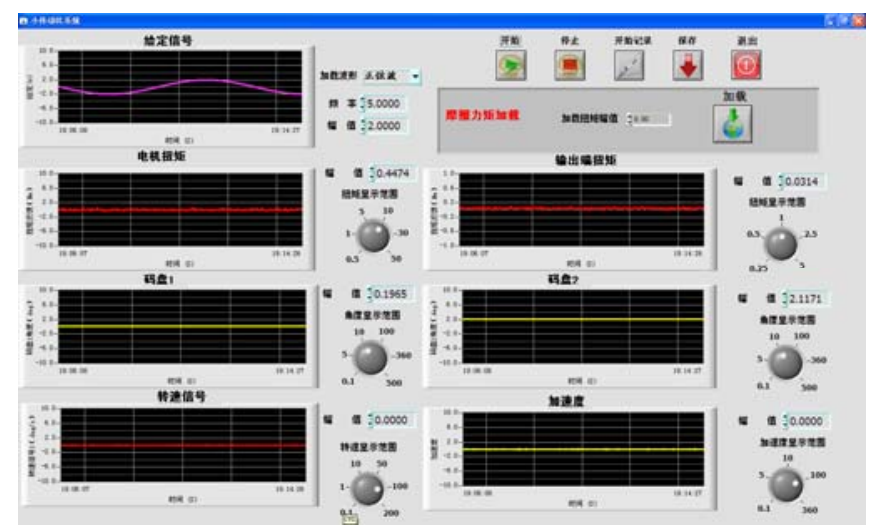

Figure 6. Interface of the measurement and control system

\section{CONCLUSION}

The performance of the test platform is shown as: the transmission ratio of the system can reach $1 \sim 10$, the moment of inertia load can reach $15 \mathrm{~kg} \cdot \mathrm{m}^{2}$, friction torque load can reach 6 $\mathrm{N} \cdot \mathrm{m}$, the range of angle measurement is $0 \sim 360^{\circ}$, the range of angular velocity measurement is $0 \sim 200^{\circ} / \mathrm{s}$, the precision of the angular velocity is $0.1 \% \mathrm{~F} \cdot \mathrm{s}$, the range of torque measurement is $0 \sim 700 \mathrm{~N} \cdot \mathrm{m}$, the precision of torque measurement is $0.5 \% \mathrm{~F} \cdot \mathrm{s}$. The test platform can truly simulate the actual load of the servo system, the research, test and experiments can be done in the platform, it can be the reference of the actual weapon system manufacture.

\section{REFERENCES}

[1] Wang jingjun and He xinpeng. Overview of artillery [M].Beijng: Arms industry press, 1992.

[2] Cao Chongmao.Topic application of soIid state synchro in a fire control system[J]. Fire ControI \& Command ControI, 1992, 19(1):21-27.

[3] Wang Guangfa.How to design the hydraulic controI system of shooting emuIation's cabin[J]. Measurement \&ControI TechnoIogy,2001,20(1):31 $-32$.

[4] ArdenceRTX 8.1 Documentation[EB/OL].http://www.ardence.com.2008

[5] Wang Xiao-Dong ,Shang Yao-Xing and Wu Shuai.Design of real-time control software with LabWindows/CVI and RTX[J]. SCIENCE \& TECHNOLOGY INFORMATION, 2008,19: 61-62.

[6] Liu Junhua. Modern detecting technology and test system design[M]. Xi'an:Xi'an Jiaotong University Press,1999:61-96.

[7] Wang jianxin, Yang shifeng and Sui meili.Test technology of LabWindows/CVI and engineering application[M].Beijing:Chemical IndustryPress, 2006 . 